Discussion Papers in Economics

Linking Consumption Externalities with Optimal Accumulation of Human and Physical Capital and Intergenerational Transfers

Monishankar Bishnu

January 2011

Discussion Paper 11-01

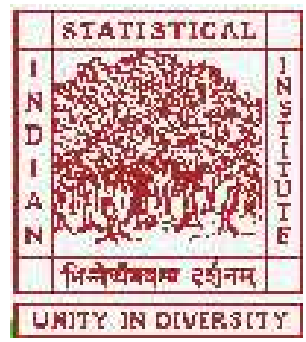

Indian Statistical Institute, Delhi

Planning Unit

7, S. J. S. Sansanwal Marg, New Delhi 110016, India 


\title{
Linking consumption externalities with optimal accumulation of human and physical capital and intergenerational transfers
}

\author{
Monisankar Bishnu* \\ Indian Statistical Institute, New Delhi
}

December 31, 2010

\begin{abstract}
While the link between consumption externalities and optimal physical capital accumulation has recently been widely studied, any discussion on the relationship between consumption externalities and optimal human capital accumulation is surprisingly absent from the literature. This paper investigates the link between consumption externalities and optimal accumulation of both types of capital (physical and human) in an unified framework. For the present purpose, I study the link in an economy where there is no spillover from human capital. This paper also opens a new perspective from which one can explain the presence of government intervention in education even in the absence of human capital externality. Traditionally, government intervention in education is justified by projecting it as a tool that corrects the distortion caused in the economy by the alleged external benefits to education. In recent times, many empirical research has questioned the existence of such externality. In this light, the findings of this paper assume particular significance. This paper also sharply departs from the existing endogenous growth models in that it distinguishes only two possible regimes of capital accumulation (as against three (Docquier et al. 2007)) when the laissez-faire and the planner's solutions are compared. The presence of consumption externalities does not generate any regime where the levels of accumulation of both types of capital (human and physical) differ from the social optimum in opposite directions. Contrary to the existing literature, the above result implies that from efficiency point of view, coexistence of both public pension benefit and education subsidy is not recommended.
\end{abstract}

Keywords : Consumption externality, human capital, education subsidy.

JEL Classification : E6, E21, H52, H55

*Planning Unit, Indian Statistical Institute, New Delhi, 7 S. J. S. Sansanwal Marg, New Delhi 110016, India. Email: mbishnu@isid.ac.in, Phone: +91-11-41493935, Fax: +91-11-41493981. 


\section{Introduction}

Docquier et al. (2007) have shown that in an economy where human capital externality is present, if the social weights assigned to the future generations by a planner are low, in the long run, competitive equilibrium overaccumulates both physical and human capital compared to what the planner would have liked. On the other hand, if the future generations are assigned high social weights, competitive equilibrium experiences underaccumulation of both types of capital. For any intermediate values of this social weight, there will be overinvestment in physical capital and underinvestment in education in the laissez-faire economy in the long run. This claim that there exists a regime where the levels of accumulation of the two types of capital (human and physical) differ from the social optimum in opposite directions raises some concern. If we include a large number of economies in the analysis, it would be much more likely to observe that human and physical capital move in the same direction. Though this is one of the major concerns, the immediate motivation behind writing the paper comes from an observation which is recently being empirically debated. While government involvement in primary and secondary education is almost universal, its presence in higher education (especially, in the form of education loans and subsidies) is also fairly common. The standard rationale for government intervention is the alleged external benefits from education: "existing graduates [will have] more graduates to talk to" [Layard, 1980]. In other words, if there are spillovers from education, then the argument is that those producing it should not bear the full cost of it (for if they were forced to, they would "undereducate" themselves). Such a human capital (measured by education) externality argument features prominently in some of the most influential work in growth theory (such as Lucas, 1988) from the last three decades. In a generational setup, the implication of this externality is that a smart generation will produce a smarter future generation. From a policy-making perspective, the human capital externality and its size is important because it determines the extent to which education and job training should be subsidized (Heckman and Klenow, 1998 and Heckman, 2000). Yet, the empirical backing for such an externality is not as strong as one would think. ${ }^{1}$ These observations help motivate a fairly broad question: how can economists rationalize such ubiquity and importance of government intervention in

\footnotetext{
${ }^{1}$ Studies involving the estimation of private and social return to education show that they are very close to each other. As Lange and Topel (2006) nicely argue that while there is no evidence that private returns are higher than the social return (and hence negative externality), the evidence that the social returns exceed the private return (and hence positive externality) is also very weak. Among others, Rudd (2000), Ciccone and Peri (2006), Yamarik (2008) also share the same view that external return to human capital is negligible. Acemoglu and Angrist (2000) too reach the same consclusion, however, somewhat arbitrarily argue that if human capital externality exists, a magnitude of 1-3\% external return is sufficient to justify public subsidies in education. As is common in growth models, I focus on human capital which is measured by education.
} 
education when direct spillovers of education are supposedly mild? ${ }^{2}$

In this paper, I show that the requirement for government intervention in education may stem from the fact that agents have consumption preferences that depend on the consumption of the other agents in the economy. That is, in the presence of consumption externalities agents may choose different levels of human and physical capital in a laissez-faire economy compared to what a planner would have preferred. In my knowledge, this paper is the first attempt of its kind to find a link between the existence of consumption externalities and optimal level of human capital production in a laissez-faire setup. The effect of consumption externalities on optimal physical capital production has recently been widely discussed. But surprisingly, in my knowledge, there has been no attempt to investigate the link between consumption externalities and optimal human capital production. This paper tries to fill in this gap. I restrict my focus within the context of a neoclassical overlapping generations (OG) model in which no intra and intergenerational human capital externalities are present and the capital market is perfect. In this setup, I argue that externalities in consumption may help make the case for public involvement in education, even in the absence of human capital externality.

The idea of a consumption externality has long been studied and documented, and involves the notion that people care not just about their own absolute level of consumption but also about how it compares to those around them. Models with interdependent preferences have become immensely popular in many areas of economics and finance. For a recent review, see Abel (2005), Alonso-Carrera et al. (2008), Barnett and Bhattacharya (2008), among others. A very general form of the externality has been used, thus allowing for the possibility of intra and intergenerational consumption externalities. More specifically an agent faces a consumption floor determined by every other agent consuming at that point in her life cycle. This is a natural extension of the keeping-up-with-the-Joneses phenomenon in that living generations compare their consumption to both their own and that of other generations alive. Though an agent's consumption type depends on the level of her human capital accumulation, consumption is more easily observable than the level of education. Thus, in layman's term, an agent's education decision crucially depends on the observed level of consumption by her neighbors. Since agents' saving behavior gets affected if they are preoccupied with "keeping up", the allocation of resources to production of human capital in the competitive economy may not be optimal.

As in Boldrin and Montes (2005) and Docquier et al. (2007), in this model too, agents

\footnotetext{
${ }^{2}$ Other popular justifications for strong government involvement in education include the following: a) credit market imperfections: see Becker (1975), Schultz (1961) and Kodde and Ritzen (1985); b) production of social capital (see Putnam et. al. (1993), Durlauf and Fafchamps (2004)); c) creating a civic society of knowledgeable voters (for e.g., Dee, (2004)).
} 
live for three periods. In the first period of their lives (i.e., when they are young), they do not consume but borrow from a perfect credit market and invest in their human capital. When middle-aged, they supply their labor inelastically, produce the final good, repay the education loan, and save in the form of physical capital. When old, they retire and consume the return on their saving. Utility is derived not from the absolute level of consumption but from the difference between the absolute and a reference level of consumption. The reference level of consumption at every time point depends on per capita consumption of the two consuming generations. Thus, a middle-aged agent not only compares her consumption to that of her peers but also to the consumption of her parents' generation. Similarly, an agent when old, keeps up with the consumption of her own peers as well as with the consumption of the middle-aged generation.

I explore the conditions under which the market economy would over or underaccumulate human capital relative to what a benevolent social planner would have deemed correct. The comparison involves a technical novelty that deserves mention. Since I solve an infinite, dynamic-planning problem with declining weights on generations to come, I have to find a way to make the market and the planning solutions directly comparable if I am to compare the allocations. I do that by devising the notion of a 'laissez-faire supported' social weight. By construction, at this specific planning discount rate, the market and planning optimality conditions coincide. However, in the presence of externality in the economy, the market solutions and planning allocations at this 'laissez-faire supported' social weight may differ. I begin the discussion by studying the effect of consumption externality at the 'laissez-faire supported' social weight, since at this particular social weight, if there is no externality in the economy, planners optimality conditions as well as the allocations coincide with that of a laissez-faire economy. The comparisons then proceed by contrasting competitive allocations with those preferred by utilitarian planners with discount rates different from this weight. The presence of the consumption externalities ensures that the decentralized market arrangement is typically not Pareto efficient. In fact, the competitive solution (assuming all markets are competitive) deviates from that of the utilitarian social planners' favored allocation in two dimensions: the market economy may over or underaccumulate both physical and human capital. The paper technically differs from Docquier et al. (2007) in the way the two sets of solutions (one for competitive equilibrium and the other for the planner's solutions) are compared and the reference level of the planner's weight is defined (see section 3). In their analysis, the benchmark social weights around which they have compared the laissez-faire and planning solutions are where the crucial variables (and hence capital stocks) are identical, that is, there exist social weights for which the capital stocks in a planner's solution equal to that in a competitive economy where human capital externality is present. 
In contrast, in my model, there exists, under some restrictions, a particular social weight, for which the planner's optimality conditions are exactly identical to that in the laissez-faire economy. However, in the absence of any consumption externality, planners optimality conditions as well as the allocations coincide with the laissez-faire one. I term this social weight a 'laissez-faire supported' social weight.

Notably, in a sharp contrast to the endogenous growth models that distinguish three possible regimes of capital accumulation, in this analysis, only two possible regimes are observed; competitive equilibrium either underaccumulates or overaccumulates both types of capital compared to the planner's solution. More interestingly, independent of its type, presence of consumption externality does not generate any regime where the levels of accumulation of two types of capital (human and physical) differ from the social optimum in opposite directions. That is, for any given type, presence of consumption externalities does not generate a regime where there is overinvestment in physical capital and at the same time underinvestment in education (and vice-versa). Also, all types of externalities, except the balanced one, extend or reduce the size of this regime. It is observed that for extremely low (high) social weight, independent of the type of the externality, competitive equilibrium overaccumulates (underaccumulates) both types of capital. However, a reasonably (not extremely) high or a reasonably low weight can lead to both underaccumulation or overaccumulation, depending on the type of the externality present in the economy. Hence a need for government intervention in education may be justified even when human capital externality is not present. It is worthwhile to note here that if a planner assigns sufficiently high weight to the future generations, the effect of consumption externality is similar to that of a human capital externality in that the justification behind implementing the standard PAYG like structure becomes weak irrespective of the type of consumption externality present. However, there are certain types of consumption externalities for which a significantly large regime of capital accumulation exists where implementing public pensions through the standard intergenerational arrangement may be justified. But, interestingly, whenever the education subsidy is justified, providing a standard public pension benefit (PAYG) is not at all desired. Thus contrary to the existing literature, implementing both education subsidy and standard public pension benefit (PAYG) to achieve efficiency is never recommended.

The rest of the paper is organized as follows. Under section 2, I present the basic framework of the economy in subsection 2.1 and subsequently in subsection 2.2, I present the competitive setup, while in subsection 2.3, a planner's first best solution in the presence of consumption externality has been characterized. I present the main results of this paper in section 3. In section 4, I present the results for a representative economy followed by the numerical results. While section 5 concludes, Appendix contains the proofs of all the 
lemmas, propositions and corollaries.

\section{The Model}

\subsection{Primitives}

I consider an economy consisting of an infinite sequence of three-period lived overlapping generations, an initial old generation, and an infinitely-lived government. In the first period of life (i.e., when they are young), agents borrow to invest in their education. They work and pay off their loans in the second period, and retire in the third period. Let $t=1,2, \ldots$ index time. The generation that works during period $t$ is indexed by $t$ and their population size is denoted by $N_{t}$. At any date $t$, the total population consists of old, middle-aged, and young agents and its size is given by $N_{t-1}+N_{t}+N_{t+1}$. The population is assumed to grow at a gross rate of $N$ or a net rate $n$ i.e., $N=1+n$. There is a single final good and it can either be consumed in the same period it is produced, or it can be stored to yield capital in the following period. Let $K_{t}$ and $H_{t}$ denote the aggregate levels of physical and human capital at date $t$ respectively, and let $h_{t} \equiv H_{t} / N_{t}$. The aggregate production function is given by $Y_{t}=F\left(K_{t}, H_{t}\right)$ where $F$ is assumed to be homogeneous of degree 1 . This assumption allows us to write $Y_{t}=H_{t} f\left(\overline{k_{t}}\right)$, where, $\overline{k_{t}} \equiv \frac{k_{t}}{h_{t}}$ and $k_{t}=\frac{K_{t}}{N_{t}}$. The function $f$ is assumed to be positive, strictly increasing and strictly concave in its argument, i.e., $f>0, f^{\prime}>0$ and $f^{\prime \prime}<0$. For reasons of analytical tractability, capital is assumed to depreciate fully between periods.

An agent belonging to generation $t$ borrows an amount $e_{t-1}$ from a perfect capital market and invests in education in period $t-1$. The education she acquires in $t-1$ translates into human capital in period $t$ as described by the production process

$$
h_{t}=\phi\left(e_{t-1}\right)
$$

where $\phi(\cdot)$ is a strictly increasing and a strictly concave function that satisfies the Inada conditions, i.e., $\phi^{\prime}(\cdot)>0, \phi^{\prime \prime}(\cdot)<0$ with $\phi^{\prime}(0)=\infty, \phi^{\prime}(\infty)=0$. As already discussed in the introduction, the construction of $h_{t}$ in this paper ensures that the production of human capital is free from the effect of any kind of externality. I now shed some light on the structure of human capital formation technology. In endogenous growth models like those used by Boldrin and Montes (2005), Docquier et al (2007) and others, the source of growth lies in the formulation of the human capital production function. In each period, human capital is generated using the human capital accumulated by their previous generation, along with the amount that the agent borrows from a perfect capital market. This specification ensures that 
there is an externality in the production of human capital since agents are born with some amount of human capital. Zhang (2003) has constructed a growth model where the human capital production function also includes the average human capital present in the economy. In this paper, I drop both the assumptions that per capita human capital production is affected by the average level of human capital in the economy and also that agents are born with some human capital. Thus I construct a human capital production function which is free from any type of externality. Galor and Moav (2006) have also worked with a similar production function, albeit in a different context, where human capital production depends only on the amount of government subsidy available. I provide a perfect capital market to guarantee that any deviation from optimal human capital production is not due to the absence of a perfect source of borrowings.

Preferences of agents play an important role in the ensuing analysis. For simplicity, I assume the young at any date do not consume. Let $c_{t}$ denote the middle-age consumption of a generation- $t$ individual and let $d_{t+1}$ denote her old-age consumption. I assume that an agent's utility depends upon her level of consumption when compared to a reference standard, i.e., on her effective level of consumption. More precisely, the lifetime utility of a generation- $t$ agent is given by

$$
u_{t}=u\left(\widehat{c}_{t}, \widehat{d}_{t+1}\right)
$$

where $\widehat{c}_{t}$ and $\widehat{d}_{t+1}$ denote the effective levels of consumption when the agent is middleaged and old respectively. This utility function is strictly increasing, strictly concave, and satisfies Inada conditions for both of its arguments. The effective level of consumption of a generation- $t$ agent is given by

$$
\widehat{c}_{t} \equiv \widehat{c}_{t}\left(c_{t}, \sigma\left(c_{t}, d_{t}\right)\right)
$$

and

$$
\widehat{d}_{t+1} \equiv \widehat{d}_{t+1}\left(d_{t+1}, \varphi\left(c_{t+1}, d_{t+1}\right)\right)
$$

where $\sigma$ and $\varphi$ are two negatively valued functions which represent the type of externalities, that is, $\sigma$ and $\varphi$ are the reference consumption levels when the agents are middle-aged and old respectively. More specifically, both of them are functions of per capita consumption of the two generations consuming at that point in time. For simplicity, I impose the condition of linearity in arguments on $\sigma$ and $\varphi$. The above formulation of preferences allows for both intragenerational consumption externality and also intergenerational consumption spillovers, that is the possibility of a generation other than one's own to influence one's consumption decision. One can define a few possible situations using the above specifications. It is worthwhile to note here that while the partial derivative $\left|\sigma_{c_{t}}\right|\left(\left|\varphi_{d_{t+1}}\right|\right)$ represents the degree 
to which a middle-aged (old) agent keeps up with the others in her own generation, $\left|\sigma_{d_{t}}\right|$ and $\left|\varphi_{c_{t+1}}\right|$ represents the degree to which the agent keeps up with the other generation. While this specification is fairly general, Barnett and Bhattacharya (2008) associate $\left|\varphi_{c_{t+1}}\right|>0$ with 'rejuvenile' behavior of the old trying to keep up with their children. These notions can also be extended based on the values of $\left|\sigma_{c_{t}}\right|,\left|\sigma_{d_{t}}\right|,\left|\varphi_{c_{t+1}}\right|$ and $\left|\varphi_{d_{t+1}}\right|$. When both $\left|\sigma_{c_{t}}\right|$ and $\left|\varphi_{c_{t+1}}\right|$ are relatively high, the weight that is given to the level of consumption of the middle-aged (the working class) in the construction of the consumption reference is high and I call it a middle-aged driven externality $[E M]$. Similarly, when both $\left|\sigma_{d_{t}}\right|$ and $\left|\varphi_{d_{t+1}}\right|$ are relatively high, it is called an old driven externality $[E O]$. Thus this general expression of utility helps us investigate many possible ways in which the consumption levels of others affects an agent's own consumption.

When middle-aged, agents supply their human capital inelastically in competitive labor markets, earning a wage rate, $w_{t}$, at time $t$, where

$$
w_{t} \equiv w\left(\bar{k}_{t}\right)=f\left(\bar{k}_{t}\right)-\bar{k}_{t} f^{\prime}\left(\bar{k}_{t}\right)
$$

and $w^{\prime}\left(\bar{k}_{t}\right)>0$. In addition, capital is traded in competitive capital markets, and earns a gross real return of $R_{t+1}$ between $t$ and $t+1$, where

$$
R_{t+1} \equiv R\left(\bar{k}_{t+1}\right)=f^{\prime}\left(\bar{k}_{t+1}\right)
$$

with $R^{\prime}\left(\bar{k}_{t+1}\right)<0 \forall t$ by the property of function $f$.

Parents in this economy are selfish and do not care for the education of their children. A generation- $t$ agent borrows amount $e_{t-1}$ in period $t-1$ at the gross interest rate $R_{t}$. The agent pays off this loan with the income earned during period $t$. The income $W_{t}$ of a middle-aged agent in period $t$ is given by $W_{t} \equiv w_{t} h_{t}-R_{t} e_{t-1}$. Thus a generation- $t$ agent's optimization problem can be written as:

$$
\max _{s_{t}, e_{t-1}} u\left(\widehat{c}_{t}, \widehat{d}_{t+1}\right)
$$

subject to

$$
c_{t}=W_{t}-s_{t}, d_{t+1}=R_{t+1} s_{t},
$$

where $s_{t} \geq 0$ denotes saving.

Assuming interior solutions and using equation (1), the solution to a generation- $t$ agent's 
problem is characterized by the following optimality conditions

$$
s_{t}: u_{\widehat{c}_{t}}=u_{\widehat{d}_{t+1}} R_{t+1} \Rightarrow \frac{u_{\widehat{c} t}}{u_{\widehat{d}_{t+1}}}=R_{t+1}
$$

and

$$
e_{t-1}: w_{t} \phi^{\prime}\left(e_{t-1}\right)=R_{t} \Rightarrow \phi^{\prime}\left(e_{t-1}\right)=\frac{R_{t}}{w_{t}}
$$

Note that $s_{t}>0 \Rightarrow W_{t}>0$. The first optimality condition (equation (4)) is straightforward. It simply describes the optimum intertemporal consumption-saving decision of the agent. In this condition, as is usual in a competitive setup, the reference externality functions are not affected by the agent's decision. The second condition (equation (5)) represents the agent's optimum expenditure decision towards education. This equation is very intuitive and can also be looked at from another angle. It guarantees that optimality is indeed reached where there is no incentive for an agent to increase her education marginally, that is, where $\frac{\partial W_{t}}{\partial e_{t-1}}=w_{t} \phi^{\prime}\left(e_{t-1}\right)-R_{t}$ equals zero. It can also be seen that this second optimality condition is not directly affected by any type of consumption externality.

\subsection{Competitive Equilibrium (CE)}

Before I formally define the competitive equilibrium, let me introduce the market clearing condition for this economy. While a part of the collective savings of the middle-aged is used to finance education for the young, the remaining amount becomes capital stock for the next period. Hence the market clearing condition can be written as $N_{t} s_{t}=K_{t+1}+N_{t+1} e_{t}$, which means

$$
s_{t}=\bar{k}_{t+1}(1+n) h_{t+1}+(1+n) e_{t} .
$$

The formal definition of a competitive equilibrium is given below.

Definition 1 A competitive equilibrium for the economy described above is a sequence of consumption allocations $\left\{c_{t}, d_{t}\right\}_{t=0}^{\infty}$, allocations of saving, capital, and education expenses, $\left\{s_{t}, k_{t}, e_{t}\right\}_{t=0}^{\infty}$, and factor prices $\left\{w_{t}, R_{t}\right\}_{t=0}^{\infty}$ that solve the agents' optimization problem at each date $t$, satisfies the market-clearing condition (6), and the factor prices satisfy (2)-(3).

Henceforth, I use the superscript $C E$ to denote the competitive equilibrium outcomes. Using equations (2)-(3), I can rewrite equations (4)-(5) as

$$
\frac{u_{\widehat{c}_{t}}^{C E}}{u_{\widehat{d}_{t+1}}^{C E}}=f^{\prime}\left(\bar{k}_{t+1}^{C E}\right)
$$


and

$$
\phi^{\prime}\left(e_{t}^{C E}\right)=\frac{f^{\prime}\left(\bar{k}_{t+1}^{C E}\right)}{f\left(\bar{k}_{t+1}^{C E}\right)-\bar{k}_{t+1}^{C E} f^{\prime}\left(\bar{k}_{t+1}^{C E}\right)},
$$

which, in turn, implies

$$
e_{t-1}^{C E}=\left(\phi^{\prime}\right)^{-1}\left(\frac{R\left(\bar{k}_{t}^{C E}\right)}{w\left(\bar{k}_{t}^{C E}\right)}\right) .
$$

The income $W_{t}$ can be re-written as

$$
\begin{aligned}
W_{t} & =w_{t} h_{t}-R_{t} e_{t-1}=w_{t} \phi\left(e_{t-1}\right)-w_{t} \phi^{\prime}\left(e_{t-1}\right) e_{t-1} \\
& =w_{t} \phi\left(e_{t-1}\left(\bar{k}_{t}\right)\right)\left[1-\eta_{h, e}\right]=w_{t}\left(\bar{k}_{t}\right) \phi\left(e_{t-1}\left(\bar{k}_{t}\right)\right)\left[1-\eta_{h, e}\left(\bar{k}_{t}\right)\right],
\end{aligned}
$$

where $\eta_{h, e}$ is the elasticity of $\phi$ with respect to $e$. Per capita saving at $t$ by the working middle-aged agent is given by

$$
s_{t}=W_{t}-c_{t}=s_{t}\left(W_{t}, d_{t}\right)=s_{t}\left(w_{t}\left(\bar{k}_{t}\right) \phi\left(e_{t-1}\left(\bar{k}_{t}\right)\right)\left[1-\eta_{h, e}\left(\bar{k}_{t}\right)\right], R_{t}\left(\bar{k}_{t}\right) s_{t-1}\right)
$$

In order to make the calculations needed to find equation (12) manageable, I assume that $\varphi=0$, i.e., the consumption of an old agent is not affected by any kind of externality. ${ }^{3}$ Using equations (11) and (6) I get the following equilibrium law of motion for the physical to human capital ratio for the economy:

$$
\begin{aligned}
s_{t}\left(w_{t}\left(\overline{k_{t}}\right) \phi\left(e_{t-1}\left(\bar{k}_{t}\right)\right)\right. & {\left[1-\eta_{h, e}\left(\bar{k}_{t}\right)\right], R_{t}\left(\bar{k}_{t}\right) \overbrace{\left[\bar{k}_{t}(1+n) \phi\left(e_{t-1}\left(\bar{k}_{t}\right)\right)+(1+n) e_{t-1}\left(\bar{k}_{t}\right)\right]}^{s_{t-1}}) } \\
= & \bar{k}_{t+1}(1+n) \phi\left(e_{t}\left(\bar{k}_{t+1}\right)\right)+(1+n) e_{t}\left(\bar{k}_{t+1}\right) .
\end{aligned}
$$

All competitive equilibrium sequences $\left\{k_{t}\right\}$ and $\left\{h_{t}\right\}$ must satisfy equation (12). A steady state equilibrium is a time-invariant sequence of $c_{t}, d_{t}, s_{t}$ and $e_{t}$. In particular, in a steady state, a time invariant $\bar{k}^{C E}$ satisfies (12).

\subsection{Social Planner's (SP) allocations}

This section deals with a planner's problem. A planner takes into account the consumption externalities ignored by individual agents. It is easy to verify that the resource constraint

\footnotetext{
${ }^{3}$ However, no such restriction has been imposed on $\varphi$ while presenting the main result. This assumption has been made only when finding the law of motion of physical to human capital ratio.
} 
for a planner can be written as:

$$
h_{t} f\left(\bar{k}_{t}\right)=c_{t}+\frac{d_{t}}{1+n}+(1+n)\left(e_{t}+k_{t+1}\right)
$$

A planner maximizes the sum of lifetime utilities of all the generations over the infinite horizon subject to the above resource constraint. I assume that generational utility is discounted by a factor $\lambda \in(0,1)$. I refer to $\lambda$ as the social weight that a planner attaches to the future generations. A high $\lambda$ implies that the social discount rate at which a planner devalues the future generations is low. In the ensuing analysis, a single planner with different social weights $\lambda$ can also be interpreted as different planners each being indexed by her own $\lambda$. The Lagrangian $^{4}$ for a generic planner's problem is as follows:

$$
£ \equiv \sum_{t=0}^{\infty} \lambda^{t}\left\{u\left(\widehat{c}_{t}, \widehat{d}_{t+1}\right)+q_{t}\left[h_{t} f\left(\bar{k}_{t}\right)-c_{t}-\frac{d_{t}}{1+n}-(1+n)\left(e_{t}+k_{t+1}\right)\right]+p_{t}\left[\phi\left(e_{t}\right)-h_{t+1}\right]\right\}
$$

where $\lambda^{t} q_{t}$ and $\lambda^{t} p_{t}$ are the multipliers associated with the resource constraint of the economy and human capital formation technology respectively, at date $t$.

The first order conditions with respect to $c_{t}^{S P}, d_{t}^{S P}, e_{t}^{S P}, k_{t+1}^{S P}$ and $h_{t+1}^{S P}$ are given below where the superscript $S P$ indicates the planner's outcome:

$$
\begin{gathered}
c_{t}^{S P}: \lambda^{t} u_{\widehat{c}_{t}}^{S P}\left(1+\sigma_{c_{t}}\right)+\lambda^{t-1} u_{\widehat{d}_{t}}^{S P} \varphi_{c_{t}}-\lambda^{t} q_{t}=0 \\
d_{t}^{S P}: \lambda^{t} u_{\widehat{c}_{t}}^{S P} \sigma_{d_{t}}+\lambda^{t-1} u_{\widehat{d}_{t}}^{S P}\left(1+\varphi_{d_{t}}\right)-\lambda^{t} \frac{q_{t}}{1+n}=0 \\
e_{t}^{S P}:-\lambda^{t}(1+n) q_{t}+\lambda^{t} p_{t} \phi^{\prime}\left(e_{t}^{S P}\right)=0 \\
k_{t+1}^{S P} \quad: \quad \lambda^{t+1} q_{t+1} h_{t+1}^{S P} f^{\prime}\left(\bar{k}_{t+1}^{S P}\right) \frac{1}{h_{t+1}^{S P}}-\lambda^{t} q_{t}(1+n)=0 \\
\quad \Rightarrow \quad q_{t}(1+n)=\lambda q_{t+1} f^{\prime}\left(\bar{k}_{t+1}^{S P}\right)
\end{gathered}
$$

${ }^{4}$ An alternative Lagrangean of the Planner's problem can be written in the following way:

$$
£ \equiv \sum_{t=0}^{\infty} \lambda^{t}\left\{u\left(\widehat{c}_{t}, \widehat{d}_{t+1}\right)+q_{t}\left[\phi\left(e_{t-1}\right) f\left(\bar{k}_{t}\right)-c_{t}-\frac{d_{t}}{1+n}-(1+n)\left(e_{t}+k_{t+1}\right)\right]\right\} .
$$

The planner chooses the path $\left\{c_{t}, d_{t}, e_{t}, k_{t+1}\right\}_{t=0}^{\infty}$. 


$$
\begin{aligned}
h_{t+1}^{S P} & : \quad \lambda^{t+1} q_{t+1}\left[h_{t+1}^{S P} f^{\prime}\left(\bar{k}_{t+1}^{S P}\right)\left(-\frac{k_{t+1}^{S P}}{\left(h_{t+1}^{S P}\right)^{2}}\right)+f\left(\bar{k}_{t+1}^{S P}\right)\right]-\lambda^{t} p_{t}=0 \\
& \Rightarrow \quad \lambda^{t+1} q_{t+1}\left[f\left(\bar{k}_{t+1}^{S P}\right)-f^{\prime}\left(\bar{k}_{t+1}^{S P}\right) \bar{k}_{t+1}^{S P}\right]-\lambda^{t} p_{t}=0 .
\end{aligned}
$$

From equations (16), (17) and (18), I have

$$
\phi^{\prime}\left(e_{t}^{S P}\right)=\frac{f^{\prime}\left(\bar{k}_{t+1}^{S P}\right)}{f\left(\bar{k}_{t+1}^{S P}\right)-f^{\prime}\left(\bar{k}_{t+1}^{S P}\right) \bar{k}_{t+1}^{S P}} .
$$

Define the 'externality factor'

$$
\Delta \equiv \frac{\left(1+\varphi_{d_{t}}\right)(1+n)-\varphi_{c_{t}}}{\left(1+\sigma_{c_{t}}\right)-\sigma_{d_{t}}(1+n)}
$$

Then, from equations (14) and (15), I have

$$
\frac{u_{\widehat{c_{t}}}^{S P}}{u_{\widehat{d_{t}}}^{S P}}=\frac{1}{\lambda} \Delta
$$

and using equations (14), (15) and (17), I can derive the following intertemporal relationship:

$$
\frac{u_{\widehat{c}_{t}}^{S P}}{u_{\widehat{d}_{t+1}}^{S P}}=f^{\prime}\left(\bar{k}_{t+1}^{S P}\right) \frac{\Delta}{1+n} .
$$

Combining the above two equations, I get

$$
\frac{u_{\widehat{d}_{t+1} P}^{S P}}{u_{\widehat{d}_{t}}^{S P}}=\frac{1}{f^{\prime}\left(\bar{k}_{t+1}^{S P}\right) \lambda}(1+n) .
$$

Note that at a steady state,

$$
f^{\prime}\left(\bar{k}^{S P}\right)=\frac{1}{\lambda}(1+n)
$$

holds. This condition defines the modified golden rule in this model. It is easy to verify that $\lambda$ and $\bar{k}^{S P}$ are positively related, which in turn implies that if a planner assigns high weight to future generations, there will be an increase in the steady state requirement of golden rule $\bar{k}^{S P}$. When there is no externality, at each $t$, a planner allocates consumption among two generations in such a way that $\lambda u_{\widehat{c}_{t}}^{S P}=u_{\widehat{d}_{t}}^{S P}$ holds, i.e., marginal utility from consumption is same for each generation. The term $\lambda$ appears because in between any two consecutive generations, the latter generation is devalued at a rate $\lambda$ by a planner. However, in the presence of externalities it has to be adjusted by the externality factor $\Delta$ (see equation 
$(21))$.

\section{Planner's choice and desirability}

A planner's choice of social weight and thus her desire to achieve a particular allocation plays a crucial role in determining the optimal levels of human and physical capital accumulation. Thus at each possible social weight, the accumulation of both types of capital in the competitive equilibrium should be compared with the planner's desired allocations. In order to be able to compare, I establish a common point around which this discussion will be meaningful. However, before I can do that, I will need to establish a few more results. All the proofs are given in the appendix.

First, it can be easily verified that for all $t, \frac{\partial \bar{k}_{t}^{i}}{\partial e_{t-1}^{i}}>0, i=C E, S P$. Naturally the result also holds in a steady state. If I denote the elasticity of $k_{t}$ with respect to $e_{t-1}$ as $\eta_{k, e}$, then it is easy to check that for every $k, h, e$ and $t, \eta_{k, e}>\eta_{h, e}$ holds, i.e., whenever the investment in education changes, the proportionate change in per capita physical capital dominates the proportionate change in human capital. It can also be verified that both $\bar{k}$ and $e^{S P}$ increase as the social weight increases. Thus a planner who attaches higher social weights to future generations guarantees a higher expenditure towards education. Since $\eta_{k, e}>\eta_{h, e}$ holds, an increase in social weight not only increases optimal per capita physical and human capital production but also the ratio of per capita physical to human capital. Thus, I have the following result.

Lemma $1 \eta_{k, e}>\eta_{h, e}$ holds for both $C E$ and $S P$. Also, at a steady state, for any $\lambda, \frac{d \bar{k}^{S P}}{d \lambda}>0$ and $\frac{d e^{S P}}{d \lambda}>0$.

The second part of Lemma 1 suggests that if the rate at which the planner discounts the future generations increases, expenditure towards education and hence the effective capital stock in the planner's solution will fall at a steady state. For a corresponding result of the second part of the above lemma in an endogenous growth framework, see Docquier et al. (2007).

In order to establish a common ground where the comparison between the laissez-faire and planning solutions is meaningful, I assume there exists a $\lambda$ (call it $\bar{\lambda}$ ) such that the optimality conditions generated by the planner's economy associated with this social weight are identical to those in the competitive economy. I also impose the additional restriction that $\bar{k}^{S P}(\bar{\lambda}) \in\left(0,\left(f^{\prime}\right)^{-1}(1+n)\right)$, where $\bar{k}^{S P}(\bar{\lambda})$ represents $\bar{k}^{S P}$ associated with the weight $\bar{\lambda}$. Note that the values that $\bar{k}^{S P}$ can take has an upper bound which is determined by the 
restriction on $\lambda$. In particular, as $\lambda \in(0,1)$, from equation (24), it is evident that as $\lambda \longrightarrow 0$, $\bar{k}^{S P} \longrightarrow 0$. On the other hand, $\bar{k}^{S P} \longrightarrow\left(f^{\prime}\right)^{-1}(1+n)$ when $\lambda \longrightarrow 1$. Since $\frac{d \bar{k}^{S P}}{d \lambda}>0$, at the steady state $\bar{k}^{S P} \in\left(0, \bar{k}_{\max }^{S P}\right)$ where $\bar{k}_{\max }^{S P}=\left(f^{\prime}\right)^{-1}(1+n)$.

At this point I should discuss the difference in the technique used to compare $C E$ and $S P$ in this paper with that in Docquier et al. (2007). Apart from the fact that their setup is different, in their analysis, the benchmark social weights around which they have compared the laissez-faire and planning solutions are where the crucial variables (and hence capital stocks) are identical. That means, in their model, there exist benchmark social weights for which the capital stocks in a planner's solution equal to that in a competitive economy. In contrast, in my model, there exists under some restrictions, a particular social weight $\bar{\lambda}$, for which the planner's optimality conditions are exactly identical to those in the competitive economy. Thus, in the absence of any consumption externality in the economy, planners optimality conditions as well as the allocations coincide with those of a competitive equilibrium. I term this social weight $\bar{\lambda}$ a 'laissez-faire supported' social weight. The existence of such $\bar{\lambda}$ requires a restriction that $\bar{k}^{S P}(\bar{\lambda}) \in\left(0, \bar{k}_{\max }^{S P}\right)$. I show if such a $\lambda=\bar{\lambda}$ exists then it must be unique. Hence the following lemma.

Lemma 2 If there exists a 'laissez-faire supported' social weight $\bar{\lambda}$ for each possible $\Delta$ where $\Delta$ is defined in equation (20), then it must be unique for each $\Delta$.

While the optimality conditions in competitive equilibrium are represented by equations (7) and (8), the corresponding optimality conditions in the planner's problem are given by equations (22) and (19). Note that equation (24) also holds. I mainly compare these two sets of conditions. In an economy with no population growth, if $\lambda=\bar{\lambda}$, it can be shown that when there is no externality present, the marginal rates of substitution are also the same. This also guarantees that when there is no externality in consumption, production of both types of capital in laissez-faire and in the planner's economy is identical. However this is not the case in the presence of externalities. I should also mention here that for simplicity of notations, I deliberately use the notation $\bar{\lambda}$ independent of the values of $\Delta$ but it is clear from the above discussion that $\bar{\lambda}$ definitely depends on $\Delta$. That is, for each possible $\Delta$, there is a $\bar{\lambda}$. There is another uniqueness result between $\bar{k}^{S P}$ and $e^{S P}$ which follows directly from equations (8) and (19) and which is stated as Lemma 3 below. The result is quite expected since there is no spillover from human capital formation.

Lemma 3 If for any $\Delta$ there exists a $\lambda=\widehat{\lambda}$ so that $\bar{k}^{S P}(\widehat{\lambda})=\bar{k}^{C E}$ holds, then the same $\hat{\lambda}$ equates $e^{S P}(\widehat{\lambda})=e^{C E}$ and vice-versa.

Now I am in a position to state the main results of the paper. For simplicity, for rest of the analysis, I assume that there is no population growth. 
Proposition 1 At a 'laissez-faire supported' social weight $\bar{\lambda}$, the presence of consumption externality does not generate any situation where the levels of accumulation of the two types of capital, human and physical, differ from the social optimum in opposite directions. That is, if $\lambda=\bar{\lambda}$, the conditions $k^{C E}>k^{S P}(\bar{\lambda})$ and $h^{C E}<h^{S P}(\bar{\lambda})$ cannot hold simultaneously at any $\Delta$. Similarly, the conditions $k^{C E}<k^{S P}(\bar{\lambda})$ and $h^{C E}>h^{S P}(\bar{\lambda})$ cannot hold simultaneously at any $\Delta$ when $\lambda=\bar{\lambda}$.

While I ultimately go on to prove that given the type of consumption externality present in the economy, there will never exist a social weight for which the production levels of the two types of capital in the competitive equilibrium differ from the social optimum in opposite directions, I start the analysis from a benchmark social weight, namely 'laissezfaire supported' social weight. Proposition 1 above states that independent of the type of consumption externality (which is characterized by the value of $\Delta$ ) present in the economy, capital accumulation in the competitive equilibrium will differ from the planner's solution in the same direction at the corresponding 'laissez-faire supported' social weight $\bar{\lambda}$. More specifically, I present the possible outcomes in the following corollary.

Corollary 1 At the 'laissez-faire supported' social weight $\bar{\lambda}$ corresponding to each possible $\Delta$, competitive equilibrium underproduces both human and physical capital compared to the planning allocation if the externality factor is greater than unity, that is, if $\Delta>1$. On the other hand, competitive equilibrium overproduces both types of capital whenever the externality factor is less than unity, that is, if $\Delta<1$.

Thus according to the above result, if the social weight is $\bar{\lambda}$ and $\Delta>1$, I have $k^{C E}<k^{S P}$ and $h^{C E}<h^{S P}$. However, if $\Delta<1$, then $k^{C E}>k^{S P}$ and $h^{C E}>h^{S P}$ hold. This result clearly says that if the externality factor is greater (less) than unity, competitive equilibrium accumulates less (greater) amount of both types of capital compared to a planner's outcome at the corresponding 'laissez-faire supported' social weight $\bar{\lambda}$, i.e., both physical and human capital production in competitive equilibrium differ from social planner's choice of capital stocks in an unidirectional way, independent of the type of externality.

It is interesting to note that $\Delta$ equals 1 in two different situations, a) when all externalities are absent, b) when $\sigma_{c_{t}}+\varphi_{c_{t}}=\sigma_{d_{t}}+\varphi_{d_{t}}$. This latter configuration is termed as 'balanced' externality. When externalities are present in both the periods, i.e., when an agent's consumption is affected by the consumption levels of other agents when she is both middle-aged and old, $\Delta>1$ is equivalent to the condition that $-\left(\sigma_{c_{t}}+\varphi_{c_{t}}\right)>-\left(\sigma_{d_{t}}+\varphi_{d_{t}}\right)$. Similarly $\Delta<1$ is equivalent to the condition that $-\left(\sigma_{c_{t}}+\varphi_{c_{t}}\right)<-\left(\sigma_{d_{t}}+\varphi_{d_{t}}\right)$. If an agent's consumption is unaffected by the consumption levels of others when she is middle-aged, 
$\Delta \gtrless 1 \Leftrightarrow-\varphi_{c_{t}} \gtrless-\varphi_{d_{t}}$. On the other hand, if there is no consumption externality when an agent is old, $\Delta \gtrless 1 \Leftrightarrow-\sigma_{c_{t}} \gtrless-\sigma_{d_{t}}$. Observe that if an economy is characterized by $E M$, i.e., the externality in consumption is driven by the middle-aged, $\Delta$ is always greater than 1. Thus by corollary 1 , in this situation, if the planner's social weight is $\bar{\lambda}$, there will be an underaccumulation of both types of capital in the competitive equilibrium relative to the planner's solution. On the other hand, when an economy is classified as EO, $\Delta$ is always less than 1 and consequently if the social weight assigned by the planner is $\bar{\lambda}$, competitive equilibrium will overproduce both types of capital compared to a planner's solution. A point to note here is that since this model allows the possibility that a planner's choice of social weight may differ from $\bar{\lambda}$, any policy prescription to correct the effects of consumption externality will depend crucially on the social weight that the planner assigns to the future generations. That a planner can choose different values of $\lambda$ helps explain many interesting cases. As an example, if a planner's social weight $\lambda$ is smaller than $\bar{\lambda}$, even in an economy characterized by $E M$, competitive equilibrium may overproduce both types of capital compared to a planner's solution. Similarly, an economy which is characterized as EO may not necessarily overproduce both physical and human capital in a laissez-faire environment. It can be shown that if a planner assigns significant weight to the future generations, an economy characterized by EO may produce less of both types of capital. Thus policy prescription for an economy crucially depends on the social weight that the planner assigns to future generations. A complete characterization of all possible situations is presented below in the next proposition.

Proposition 2 If the planner's social weight to the future generation, $\lambda$, exceeds (is less than) the 'laissez-faire supported' social weight $\bar{\lambda}$, there does not exist any situation where the levels of accumulation of two types of capital, human and physical, differ from the social optimum in opposite directions. Furthermore, underaccumulation (overaccumulation) of capital for all types of externality occur at a weight which is higher (lower) than the 'laissez-faire supported' social weight.

By the virtue of Proposition 1 and Corollary 1, it is known that when a planner's choice of social weight is $\bar{\lambda}$, there does not exist any situation where the levels of accumulation of physical and human capital in the competitive equilibrium differ from the planner's outcome in opposite directions. Proposition 2 states that capital stocks in the competitive equilibrium differ from the planner's solution in an unidirectional way even when the social weight is different from $\bar{\lambda}$. Thus propositions 1 and 2 indicate that in every possible regime, accumulation of both types of capital in the competitive equilibrium differs from the planner's choice in an unidirectional way, i.e., there is either underaccumulation or overaccumulation of both 
human and physical capital. The following two corollaries clearly distinguish the different possible regimes of capital accumulation and thereafter explain how the type of consumption externality present in the economy determines whether the competitive equilibrium will under or overaccumulate both types of capital.

Corollary 2 If the externality factor is less than unity, there exists a social weight $\lambda_{+}>\bar{\lambda}$ such that whenever the planner's weight exceeds $\lambda_{+}$, competitive equilibrium underaccumulates both types of capital. For any $\lambda<\lambda_{+}$, competitive equilibrium overaccumulates both types of capital. However, if the externality factor is greater than or equal to unity, assigning a weight higher than the respective $\bar{\lambda}$ implies further underaccumulation of both types of capital in the competitive economy.

The above corollary specifies that if $\Delta \geq 1$ and $\lambda>\bar{\lambda}$, I clearly have $h^{S P}(\lambda)>h^{C E}$ and $k^{S P}(\lambda)>k^{C E}$. On the other hand if $\Delta<1, h^{S P}(\lambda)<h^{C E}$ and $k^{S P}(\lambda)<k^{C E}$ whenever the social weight $\lambda \in\left[\bar{\lambda}, \lambda_{+}\right]$. But when the social weight $\lambda>\lambda_{+}, h^{S P}(\lambda)>h^{C E}$ and $k^{S P}(\lambda)>k^{C E}$ will always hold. Assigning a high future weight necessarily results high production of both physical and human capital in the economy. If the externality factor is greater than or equal to one, any weight greater than the 'laissez-faire supported' weight guarantees more production of both types of capital by the planner and the competitive equilibrium relatively underproduces. However, when the externality factor is less than unity, underaccumulation in competitive equilibrium starts from a weight which is higher than the 'laissez-faire supported' weight.

Corollary 3 If the externality factor is greater than unity, there exists a social weight $\lambda_{-}<\bar{\lambda}$ such that whenever the planner's weight is less than $\lambda_{-}$, competitive equilibrium overaccumulates both types of capital. For any $\lambda>\lambda_{-}$, competitive equilibrium underaccumulates both types of capital. However, if the externality factor is less than or equal to unity, assigning a weight lower than $\bar{\lambda}$ implies further overaccumulation of both types of capital in the competitive economy.

Thus, if $\Delta \leq 1$ and $\lambda<\bar{\lambda}$ holds, where $\bar{\lambda}$ is the 'laissez-faire supported' social weight for that particular $\Delta$, there will be overaccumulation of both human and physical capital in the competitive equilibrium, i.e., $h^{S P}(\lambda)<h^{C E}$ and $k^{S P}(\lambda)<k^{C E}$. On the other hand, if $\Delta>1, h^{S P}(\lambda)>h^{C E}$ and $k^{S P}(\lambda)>k^{C E}$ will hold whenever the social weight $\lambda \in\left[\lambda_{-}, \bar{\lambda}\right]$. However, at that same value of $\Delta$, if $\lambda<\lambda_{-}$, competitive equilibrium will overaccumulate both types of capital. The above two corollaries guarantee that the presence of externality reduces or increases the regime of under or overaccumulation. For example, when there is 
no consumption externality present or the externality is balanced, i.e., $\Delta=1$, underaccumulation of capital in competitive equilibrium occurs at the social weight $\bar{\lambda}$. However, if externality is present and say the externality factor is less than unity, overaccumulation is experienced up to $\lambda_{+}>\bar{\lambda}$, which means that the regime of overaccumulation is now extended to $\lambda_{+}$and consequently the regime of underacculation gets reduced. Similarly when the externality factor exceeds unity, the regime of overaccumulation now becomes smaller. In this case, the regime of underaccumulation starts after $\lambda_{-}<\bar{\lambda}$ which means that the regime of underaccumulation now gets extended. The following diagram which represents the regions of accumulation based on the types of externalities present, makes the above discussion clear.

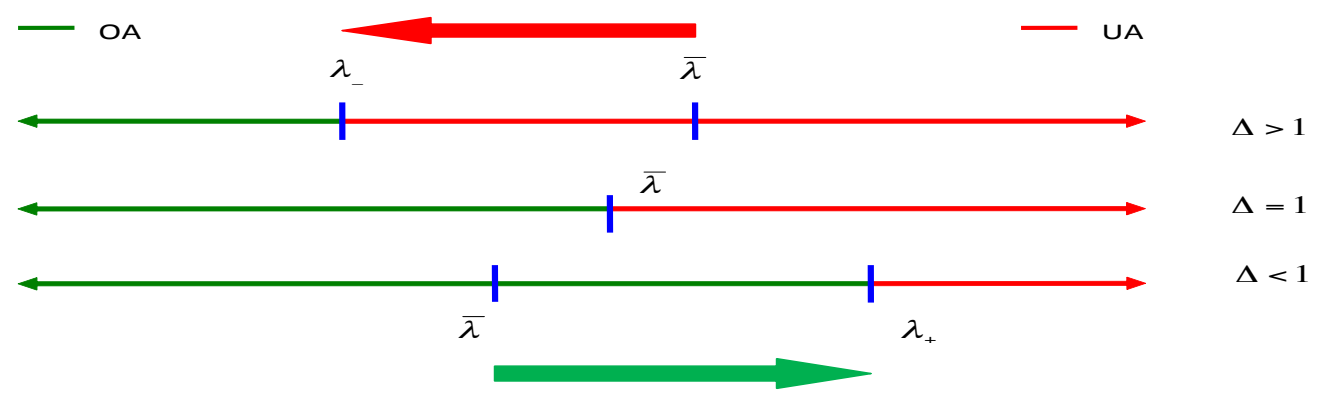

Fig. 1. Capital accumulation regimes under different externalities.

In this paragraph and the next I discuss the intuition behind the above results. All the different types of externalities and their corresponding effects can well be explained by the above results. I have clearly explained the situations where $\Delta \gtreqless 1$ holds. Note that when $\lambda=\bar{\lambda}$, if I set $\varphi=0$, then $\Delta>1 \Rightarrow-\sigma_{c_{t}}>-\sigma_{d_{t}}$ or $\left|\sigma_{c_{t}}\right|>\left|\sigma_{d_{t}}\right|$. That is, externality is present only when the agent is middle-aged. Let me explain why there is an underaccumulation of both types of capital in this scenario at the 'laissez-faire supported' social weight. Since middle-aged consumption has a high benchmark reference level ${ }^{5}$, at a steady state, because of this high consumption, saving falls. This reduction in saving lowers the production of physical capital as a result of which the ratio of physical to human capital also falls at a given level of human capital. This fall in the ratio of physical to human capital makes cost of capital high as well as wage rate low at a given level of human capital. Thus, a reduction in saving through its effect on the ratio of physical to human capital makes cost of capital high and the wage rate low at a given level of human capital. Furthermore, since this high cost of capital and low wage rate reduce the incentive for young generation to borrow, this not only reduces the level of human capital accumulation but also reduces the

\footnotetext{
${ }^{5}$ Note that lineratity of $\sigma$ and $\varphi$ in its arguments guarantees that the partial derivatives of $\sigma$ and $\varphi$ are time invariant, that is, $\sigma_{c_{t}}=\sigma_{c_{t+1}}, \sigma_{d_{t}}=\sigma_{d_{t+1}}$ and $\varphi_{c_{t}}=\varphi_{c_{t+1}}, \varphi_{d_{t}}=\varphi_{d_{t+1}}$ for all $t$.
} 
production of physical capital even further. Therefore the ratio of physical to human capital falls further since $\eta_{k, e}>\eta_{h, e}$ holds (see Lemma 1). When $\sigma=0, \Delta>1 \Rightarrow-\varphi_{c_{t}}>-\varphi_{d_{t}}$ or $\left|\varphi_{c_{t}}\right|>\left|\varphi_{d_{t}}\right|$. In this case there is no benchmark consumption when agents are middle-aged. But since an old agent's affinity towards middle-aged consumption is high, at the steady state, this increases her middle-aged consumption too. Therefore the saving falls and the retrospective effects can be observed.

In the case of $E M$ where there is underaccumulation of capital (under $\lambda=\bar{\lambda}$ ), observe that at a steady state, overconsumption by the middle-aged agents leads to a reduction in savings which in turn by the virtue of the market clearing condition guarantees less per capita physical capital as well as less human capital production in the competitive equilibrium. Also, a fall in physical capital increases the cost of capital and decreases the wage rate. This in turn makes borrowing for human capital production less attractive. But if the weight assigned by a planner to the future generation is very low, it inversely affects (see Lemma 1) both physical and human capital production and thus leads to a lower level of physical and human capital at the social optimum. Therefore, in this situation where a planner's social weight is very low, an $E M$ economy will overproduce both types of capital in a laissez-faire setup. Similarly, in the case of $E O$, equilibrium overconsumption by the old generation (under $\lambda=\bar{\lambda}$ ) leads to an increase in saving which in turn results in a greater production of both physical and human capital. But if the social weight is high, optimal capital production in a planner's economy increases (see Lemma 1) which in turn raises the possibility that the laissez-faire economy underproduces compared to a planner's economy. Note that though I had started the discussion by finding out a specific $\lambda=\bar{\lambda}$, it is now clear from the results that one can compare the solutions of competitive equilibrium and the social planner's for the entire range of the possible values of the social weight. The same explanation at the steady state for different possible values of $\Delta$ can be provided when externalities are present in both the generations.

The above results guarantee that unlike the effect of human capital externality, in the presence of consumption externality, there does not exist any regime where the capital accumulation in competitive equilibrium is such, that there is overinvestment in physical capital and underinvestment in human capital at the same time, when compared to the planner's allocation. This result holds true irrespective of the type of consumption externality present. Obviously, there are many possible ways to achieve the planner's solution. However, the more interesting case is where one focuses solely on the intergenerational transfers which take care of optimal physical capital accumulation along with an arrangement for young to borrow funds for education. If the focus is only on the alleviation of the effect of externality, it is clear from the model that similar to endogenous growth models, a transfer between genera- 
tions can help the production of physical capital stock to reach the optimal level. If a planner assigns very high weights to the future generations, independent of the type of consumption externalities present, the justification behind implementing the standard public pension benefits where physical capital moves away from the present working class to the present old becomes reasonably weak. However, there are certain types of consumption externalities for which a significant regime of capital accumulation exists where implementing public pensions through the standard intergenerational arrangement may be justified. But from the efficiency point of view, whenever a standard public pension scheme is introduced when there is overaccumulation of physical capital, an education subsidy becomes unnecessary since an overaccumulation of physical capital is also accompanied by an overaccumulations in human capital. Similarly, I can argue that whenever an education subsidy is required because of underaccumulation in human capital, a standard public pension benefit is not recommended since an underaccumulation in human capital accompanies an underaccumulation in physical capital too.

\section{An example}

In this section I present my claims through an example. Consider the following representation of human capital and final good production technology respectively.

$$
\begin{gathered}
h_{t}=\phi\left(e_{t-1}\right)=A e_{t-1}^{\alpha}, \alpha \in(0,1), A>0 \\
f\left(\bar{k}_{t}\right)=B \bar{k}_{t}^{\beta}, \beta \in(0,1), B>0 .
\end{gathered}
$$

Here I specify the consumption patterns in the following way so that I can construct an externality like Alonso - Carrera et al. (2008) where the effective levels of consumption of a generation- $t$ agent is given by

$$
\widehat{c}_{t}=c_{t}-\gamma v_{t}^{m}
$$

and

$$
\widehat{d}_{t+1}=d_{t+1}-\delta v_{t+1}^{o},
$$

where $\gamma \in[0,1)$ and $\delta \in[0,1)$ measure the intensity of the consumption references, $v_{t}^{m}$ and $v_{t+1}^{o}$, respectively. The consumption benchmarks in any period are assumed to be a weighted arithmetic average of the per-capita consumption of the two generations consuming in that period. Specifically,

$$
v_{t}^{m} \equiv \frac{N_{t} c_{t}+\theta^{m} N_{t-1} d_{t}}{N_{t}+\theta^{m} N_{t-1}}=\left(\frac{N}{N+\theta^{m}}\right) c_{t}+\left(\frac{\theta^{m}}{N+\theta^{m}}\right) d_{t},
$$


where $\theta^{m} \in[0,1]$ is the weight of a representative old agent's consumption in the specification of the middle-aged agent's consumption benchmark. Similarly

$$
v_{t+1}^{o} \equiv \frac{\theta^{o} N_{t+1} c_{t+1}+N_{t} d_{t+1}}{\theta^{o} N_{t+1}+N_{t}}=\left(\frac{\theta^{o} N}{\theta^{o} N+1}\right) c_{t+1}+\left(\frac{1}{\theta^{o} N+1}\right) d_{t+1},
$$

where $\theta^{o} \in[0,1]$ is the weight of a representative middle-aged agent's consumption in the specification of an old agent's consumption reference. Denoting $\frac{N}{N+\theta^{m}} \equiv \varepsilon^{m}$ and $\frac{\theta^{o} N}{\theta^{\circ} N+1} \equiv \varepsilon^{o}$ gives $v_{t}^{m}=\varepsilon^{m} c_{t}+\left(1-\varepsilon^{m}\right) d_{t}$ and $v_{t+1}^{o} \equiv \varepsilon^{o} c_{t+1}+\left(1-\varepsilon^{o}\right) d_{t+1}$. This specification implies that $\sigma \equiv-\gamma\left[\varepsilon^{m} c_{t}+\left(1-\varepsilon^{m}\right) d_{t}\right]$ and $\varphi \equiv-\delta\left[\varepsilon^{o} c_{t+1}+\left(1-\varepsilon^{o}\right) d_{t+1}\right]$. We specify lifetime utility as a log-linear function of consumption as shown below

$$
u_{t}\left(\widehat{c}_{t}, \widehat{d}_{t+1}\right)=\log \left(c_{t}-\gamma v_{t}^{m}\right)+\rho \log \left(d_{t+1}-\delta v_{t+1}^{o}\right)
$$

where $\rho \in(0,1)$ is the intertemporal discount factor.

The strength of these influences depend on the deeper parameters $\theta^{m}$ and $\theta^{o}$. Versions of these preferences have been used by Abel (2005). ${ }^{6}$ In this specification, while $\varepsilon^{m}\left(\left(1-\varepsilon^{o}\right)\right)$ represents the degree to which a middle-aged (old) agent keeps up with the others in her own generation, $\left(1-\varepsilon^{m}\right)$ and $\varepsilon^{o}$ represents the degree to which the agent keeps up with the other generation. When both $\varepsilon^{m}$ and $\varepsilon^{o}$ are high, the weight that is given to the level of consumption of the middle-aged (the working class) in the construction of the consumption reference is high, I call it a middle-aged driven externality $[E M]$. Similarly, when both $\varepsilon^{m}$ and $\varepsilon^{o}$ are low, it is called an old driven externality $[E O]$. More specifically, in this particular example, I use the term 'high' when the coefficients exceed the number $\frac{1}{2}$. Now I start with a competitive setup and then define the competitive equilibrium in this economy.

Using equations (2), (3) and (9) I get

$$
\phi^{\prime}\left(e_{t-1}\right)=\frac{R_{t}}{w_{t}}=\frac{\beta B \bar{k}_{t}^{\beta-1}}{(1-\beta) B \bar{k}_{t}^{\beta}}=\frac{\beta}{(1-\beta) \bar{k}_{t}}
$$

and from equation (4) I have

$$
\frac{1}{\left(c_{t}-\gamma v_{t}^{m}\right)}=\rho \frac{1}{\left(d_{t+1}-\delta v_{t+1}^{o}\right)} R_{t+1}
$$

\footnotetext{
${ }^{6}$ In this example, the form of externalities used differs from the one used in Abel (2005). In Abel (2005) the reference consumption is of a multiplicative form and depends on the levels of consumption of two different generations at a particular time point. Furthermore the reference consumption level affects the utility of an agent's consumption multiplicatively. Here the reference consumption level has been constructed additively and unlike Abel (2005) effective consumption is determined by subtracting the reference consumption level from the actuals.
} 
along with

$$
\begin{gathered}
c_{t}=w_{t} h_{t}-R_{t} e_{t-1}-s_{t} \\
d_{t+1}=R_{t+1} s_{t} .
\end{gathered}
$$

For simplicity if I assume that $n=0$ and define

$$
\begin{gathered}
Z_{1} \equiv \frac{\alpha^{\frac{\alpha}{1-\alpha}} \beta^{\frac{\alpha}{\alpha-1}}(1-\alpha)(1-\beta)^{\frac{1}{1-\alpha}} \rho\left(1-\gamma \varepsilon^{m}\right) A B}{1+\rho\left(1-\gamma \varepsilon^{m}\right)} \\
Z_{2} \equiv \frac{\gamma \rho\left(1-\varepsilon^{m}\right) \beta B}{1+\rho\left(1-\gamma \varepsilon^{m}\right)}
\end{gathered}
$$

and

$$
Z_{3} \equiv \frac{\left\{\alpha^{\frac{\alpha}{\alpha-1}} \beta^{\frac{\alpha}{\alpha-1}}(1-\beta)^{\frac{\alpha}{\alpha-1}}+\alpha^{\frac{1}{1-\alpha}} \beta^{\frac{1}{\alpha-1}}(1-\beta)^{\frac{1}{1-\alpha}}\right\} A^{\frac{1}{1-\alpha}}}{1+\rho\left(1-\gamma \varepsilon^{m}\right)},
$$

I can show that the path of $\left\{\bar{k}_{t}\right\}_{t=0}^{\infty}$ can be written as

$$
\bar{k}_{t+1}=\left(\frac{Z_{1}-Z_{2} Z_{3}}{Z_{3}}\right)^{1-\alpha} \bar{k}_{t}^{\alpha+\beta-\alpha \beta} .
$$

Given the specification of the economy, since $\alpha+\beta-\alpha \beta<1$ always holds, the path of $\left\{\bar{k}_{t}\right\}_{t=0}^{\infty}$ is a concave function. Then, if $\left(Z_{1}-Z_{2} Z_{3}\right)>0$, the model guarantees a positive savings which in turn implies that

$$
\frac{\left(1-\gamma \varepsilon^{m}\right)}{\gamma\left(1-\varepsilon^{m}\right)}>\frac{\alpha+\beta-\alpha \beta}{(1-\alpha)(1-\beta)}
$$

Note that the left hand side decreases with $\gamma$ but increases with $\varepsilon^{m}$. Along the steady state, I get

$$
\bar{k}^{C E}=\left(\frac{Z_{1}-Z_{2} Z_{3}}{Z_{3}}\right)^{\frac{1-\alpha}{1-\alpha-\beta+\alpha \beta}} .
$$

The Lagrangian for the planner's problem (before setting $n=0$ ) is as follows:

$$
£ \equiv \sum_{t=0}^{\infty} \lambda^{t}\left\{u\left(\widehat{c}_{t}, \widehat{d}_{t+1}\right)+q_{t}\left[h_{t} f\left(\bar{k}_{t}\right)-c_{t}-\frac{d_{t}}{1+n}-(1+n)\left(e_{t}+k_{t+1}\right)\right]+p_{t}\left[\phi\left(e_{t}\right)-h_{t+1}\right]\right\}
$$

The first order conditions with respect to $c_{t}^{S P}, d_{t}^{S P}, e_{t}^{S P}, k_{t+1}^{S P}$ and $h_{t+1}^{S P}$ are given below:

$$
c_{t}^{S P}: \lambda^{t} u_{\widehat{c}_{t}}^{S P}\left(1-\gamma \varepsilon^{m}\right)-\lambda^{t-1} u_{\widehat{d}_{t}}^{S P} \delta \varepsilon^{o}-\lambda^{t} q_{t}=0
$$




$$
\begin{gathered}
d_{t}^{S P}:-\lambda^{t} u_{\widehat{c}_{t}}^{S P}\left(1-\varepsilon^{m}\right) \gamma+\lambda^{t-1} u_{\widehat{d}_{t}}^{S P}\left(1-\delta\left(1-\varepsilon^{o}\right)\right)-\lambda^{t} \frac{q_{t}}{1+n}=0 \\
e_{t}^{S P}:-\lambda^{t}(1+n) q_{t}+\lambda^{t} p_{t} \phi^{\prime}\left(e_{t}^{S P}\right)=0 \\
k_{t+1}^{S P} \quad: \quad \lambda^{t+1} q_{t+1} h_{t+1}^{S P} f^{\prime}\left(\bar{k}_{t+1}^{S P}\right) \frac{1}{h_{t+1}^{S P}}-\lambda^{t} q_{t}(1+n)=0 \\
\Rightarrow \quad q_{t}(1+n)=\lambda q_{t+1} f^{\prime}\left(\bar{k}_{t+1}^{S P}\right) \\
\quad: \quad \lambda^{t+1} q_{t+1}\left[h_{t+1}^{S P} f^{\prime}\left(\bar{k}_{t+1}^{S P}\right)\left(-\frac{k_{t+1}^{S P}}{\left(h_{t+1}^{S P}\right)^{2}}\right)+f\left(\bar{k}_{t+1}^{S P}\right)\right]-\lambda^{t} p_{t}=0 \\
h_{t+1}^{S P} \quad \lambda^{t+1} q_{t+1}\left[f\left(\bar{k}_{t+1}^{S P}\right)-f^{\prime}\left(\bar{k}_{t+1}^{S P}\right) \bar{k}_{t+1}^{S P}\right]-\lambda^{t} p_{t}=0 .
\end{gathered}
$$

Using equations (33), (34) and (35), I get

$$
\phi^{\prime}\left(e_{t}^{S P}\right)=\frac{f^{\prime}\left(\bar{k}_{t+1}^{S P}\right)}{f\left(\bar{k}_{t+1}^{S P}\right)-f^{\prime}\left(\bar{k}_{t+1}^{S P}\right) \bar{k}_{t+1}^{S P}} .
$$

The externality factor $\Delta$ in this example turns out to be

$$
\Delta \equiv \frac{\delta \varepsilon^{o}+\left\{1-\delta\left(1-\varepsilon^{o}\right)\right\}(1+n)}{\left(1-\gamma \varepsilon^{m}\right)+\left(1-\varepsilon^{m}\right) \gamma(1+n)} .
$$

Therefore from equations (31) and (32), I have

$$
\frac{u_{\widehat{c} t}^{S P}}{u_{\widehat{d} t}^{S P}}=\frac{1}{\lambda} \Delta
$$

and using equations (31), (32) and (34), I derive the intertemporal condition as follows:

$$
\frac{u_{\widehat{c}_{t}}^{S P}}{u_{\widehat{d}_{t+1}}^{S P}}=f^{\prime}\left(\bar{k}_{t+1}^{S P}\right) \frac{\Delta}{1+n} .
$$

Combining the last two equations, I have

$$
\frac{u_{\widehat{d}_{t+1}}^{S P}}{u_{\widehat{d}_{t}}^{S P}}=\frac{1}{f^{\prime}\left(\bar{k}_{t+1}^{S P}\right) \lambda}(1+n)
$$

and thus at a steady state,

$$
f^{\prime}\left(\bar{k}^{S P}\right)=\frac{1}{\lambda}(1+n)
$$


Therefore I can compute $\bar{\lambda}$ by equating $f^{\prime}\left(\bar{k}^{C E}\right)=\frac{\Delta}{\bar{\lambda}}$. Consequently $\bar{k}^{S P}$ can be calculated by $\bar{k}^{S P}=\left(f^{\prime}\right)^{-1}\left(\frac{1}{\bar{\lambda}}\right)$ where in this example, $\bar{k}^{S P}=(\bar{\lambda} \beta B)^{\frac{1}{1-\beta}}$ at $\bar{\lambda}$.

After I set $n=0$, it is worthwhile to note that $\Delta=1$ occurs in two different situations, a) when there are no externalities present and, b) when $\frac{\delta}{\delta+\gamma} \varepsilon^{o}+\frac{\gamma}{\delta+\gamma} \varepsilon^{m}=\frac{1}{2}$ or $\frac{\delta}{\delta+\gamma}\left(1-\varepsilon^{o}\right)+$ $\frac{\gamma}{\delta+\gamma}\left(1-\varepsilon^{m}\right)=\frac{1}{2}, \delta, \gamma \neq 0$. When externalities are present in both the periods, i.e., when an agent's consumption is affected by externalities when she is both middle-aged and old, $\Delta \gtrless 1 \Rightarrow \frac{\delta}{\delta+\gamma} \varepsilon^{o}+\frac{\gamma}{\delta+\gamma} \varepsilon^{m} \gtrless \frac{1}{2} \Leftrightarrow \frac{\delta}{\delta+\gamma}\left(1-\varepsilon^{o}\right)+\frac{\gamma}{\delta+\gamma}\left(1-\varepsilon^{m}\right) \lessgtr \frac{1}{2}$. It is easy to check that if there is no consumption externality when the agent is middle-aged that is $\sigma=0$ by setting $\gamma=0$, $\Delta \gtrless 1 \Leftrightarrow \varepsilon^{o} \gtrless \frac{1}{2}$. On the other hand, if there is no consumption externality present when an agent is old, that is $\varphi=0$ by assigning $\delta=0$, we have $\Delta \gtrless 1 \Leftrightarrow \varepsilon^{m} \gtrless \frac{1}{2}$. Thus $\Delta>1$ or $\Delta<1$ occurs in many different situations. We can easily observe that if the economy is characterized by $E M$, we will always have $\Delta>1$. This means that in this situation, if the planner's social weight is $\bar{\lambda}$, competitive equilibrium underaccumulates both types of capital as compared to the planner's solution. On the other hand, when the economy is classified as $E O$, at $\bar{\lambda}$, competitive equilibrium overproduces both types of capital when compared to a planner's allocations. A few other possible scenarios based on the type of externalities can also be explained from here.

To represent all possible capital accumulations regime vis-a-vis competitive and planner's solution, I assume the following parametric specifications: $\alpha=0.2, \beta=0.33, A=10$, $B=10, \rho=0.9$. The two propositions (and corollaries) that I presented above can well be verified for this economy. I compute the steady state values of $\left\{\bar{k}^{C E}, k^{C E}, h^{C E}\right\}$ and $\left\{\bar{k}^{S P}, k^{S P}, h^{S P}\right\}$ that are shown in Table 1 below for different parametric values of $\gamma$ and $\varepsilon^{m}$.

\begin{tabular}{|l|l|l|l|l|l|l|}
\hline Cases & $\gamma$ & $\varepsilon^{m}$ & $\bar{\lambda}$ & $\Delta$ & $\left\{\bar{k}^{C E}, h^{C E}, k^{C E}\right\}$ & $\left\{\bar{k}^{S P}, h^{S P}, k^{S P}\right\}$ \\
\hline$(1)$ & 0.9 & 0.9 & 0.3554 & 3.5714 & $\{0.1898,2.3434,0.4447\}$ & $\{1.2687,3.7682,4.7807\}$ \\
\hline$(2)$ & 0.9 & 0.2 & 0.0764 & 0.6494 & $\{0.2437,2.4946,0.6079\}$ & $\{0.1279,2.1234,0.2716\}$ \\
\hline$(3)$ & 0.2 & 0.9 & 0.5716 & 1.1905 & $\{1.9877,4.2158,8.3799\}$ & $\{2.5785,4.4992,11.6013\}$ \\
\hline$(4)$ & 1 & 0.5 & 0.0482 & 1.000 & $\{0.2251,2.4456,0.5505\}$ & $\{0.2251,2.4456,0.5505\}$ \\
\hline
\end{tabular}

Table 1. Equilibrium at laissez-faire vis-a-vis social optimum at $\bar{\lambda}$.

It has already been established that the choice of $\bar{\lambda}$ depends on the value of $\Delta$. I pick case (1) from Table 1 where the value of $\Delta$ is greater than 1 and $\bar{\lambda}=0.3554$. I choose two possible values of $\lambda$, both being less than $\bar{\lambda}=0.3554$. This result is shown as case $\left(1^{\prime}\right)$ in Table 2. When $\lambda=0.34$, competitive equilibrium underproduces and when $\lambda=.034$, competitive equilibrium overproduces both types of capital. This guarantees that there exists 
a $\lambda=\lambda_{-}=0.0995$ where $h^{C E}=h^{S P}$ and $k^{C E}=k^{S P}$. Similarly, in $\left(2^{\prime}\right)$, where $\Delta$ is less than 1 , I choose two possible values of $\lambda$ both of which are greater than the corresponding $\bar{\lambda}=0.0764$ (see case (2) in Table 1 ). Observe that in one situation $(\lambda=0.09)$, competitive equilibrium overproduces while in the other $(\lambda=0.9)$, it underproduces both types of capital compared to the planner's economy. This then confirms that there exists a $\lambda=\lambda_{+}=0.1177$ so that at $\lambda_{+}, h^{C E}=h^{S P}$ and $k^{C E}=k^{S P}$.

\begin{tabular}{|c|c|c|c|c|c|c|}
\hline Cases & $\gamma$ & $\varepsilon^{m}$ & $\lambda$ & $\Delta$ & $\left\{\bar{k}^{C E}, h^{C E}, k^{C E}\right\}$ & $\left\{\bar{k}^{S P}, h^{S P}, k^{S P}\right\}$ \\
\hline$\left(1^{\prime}\right)$ & 0.9 & 0.9 & $\begin{array}{l}0.3400 \\
0.0995\left(\lambda_{-}\right) \\
0.0340\end{array}$ & 3.5714 & $\{0.1898,2.3434,0.4447\}$ & $\begin{array}{l}\{1.1875,3.7063,4.4011\} \\
\{0.1898,2.3434,0.4447\} \\
\{0.0382,1.5697,0.0600\}\end{array}$ \\
\hline$\left(2^{\prime}\right)$ & 0.9 & 0.2 & $\begin{array}{l}0.0900 \\
0.1177\left(\lambda_{+}\right) \\
0.9000\end{array}$ & 0.6494 & $\{0.2437,2.4946,0.6079\}$ & $\begin{array}{l}\{0.1633,2.2571,0.3687\} \\
\{0.2437,2.4946,0.6079\} \\
\{5.0770,5.3296,27.0582\}\end{array}$ \\
\hline
\end{tabular}

Table 2. Existence of $\lambda_{-}$and $\lambda_{+}$.

The above two cases have been represented below in two diagrams. While the capital accumulations (pc and hc stand for physical and human capital respectively in the diagrams) in competitive equilibrium are shown as horizontally straight lines (since it does not vary with the social weight), dotted curves represent the accumulation in the planners economy. Vertical lines represent the benchmark social weights - while the dotted vertical line represents $\bar{\lambda}$ and associated capital levels, the solid line represents the associated $\lambda$ for which the levels of accumulation are same in competitive equilibrium and in the planner's solution. In Figure 2 the bold vertical line is essentially $\lambda_{-}$and in Figure 3 it represents $\lambda_{+}$. In case $\left(1^{\prime}\right)$, it can be observed that competitive equilibrium overaccumulates up to $\lambda_{-}$after which it underaccumulates as social weight starts increasing. On the other hand in case $\left(2^{\prime}\right)$, competitive equilibrium overaccumulates till $\lambda_{+}$after which accumulation in planner's solution is much higher compared to the competitive equilibrium. 


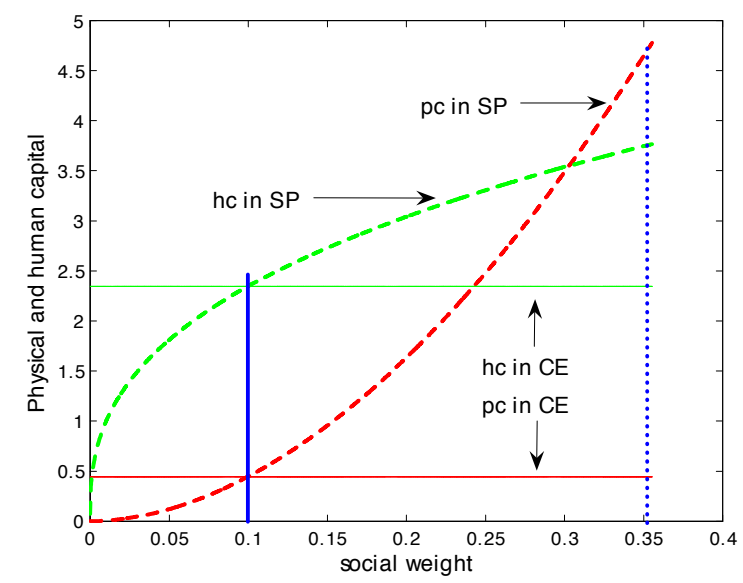

Fig. 2. Case $\left(1^{\prime}\right)$

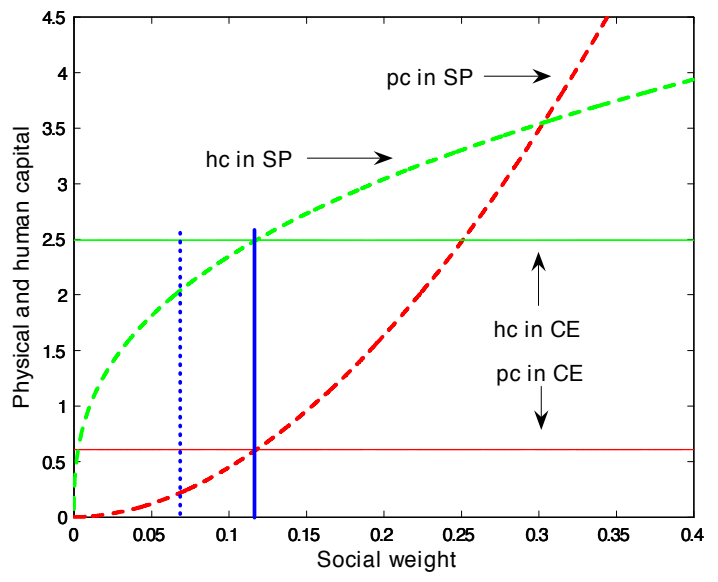

Fig. 3. Case $\left(2^{\prime}\right)$

\section{Conclusion}

Governments commonly intervene in education, typically in the form of education loans and subsidies. The standard rationale for such intervention is a human capital externality: for the same effort, people learn more if they are around smart people. The intergenerational counterpart of this observation is that a smart generation produces a smarter future generation. This paper makes the case for government intervention in education even when no human capital externalities are present. ${ }^{7}$ However, the requirement for education subsidy may actually stem from the presence of consumption externality. That is, in this paper, it is the consumption externality that motivates agents to acquire a different level of education than what a planner would have liked. In my knowledge, this important link has been ignored in the literature. To present this result a neoclassical overlapping generations model of human and physical capital accumulation is studied. Children borrow from perfect capital markets to fund education expenses. When middle-aged, they earn income from human capital, and save in the form of physical capital. Agents are assumed to care not

\footnotetext{
${ }^{7}$ There are alternative ways to achieve efficiency. I do not claim that provision of direct government involvement in education is the unique efficient way. For example, staying away from using generational transfer instruments, a tax or a subsidy (enough to correct the effects of the consumption externality) on capital income, along with a lump-sum transfer back to the same generation can implement the planner's solution; also see Richter and Braun (2010). While such alternatives somewhat weaken the case for direct government involvement in education, it can be argued that many countries find it considerably difficult to employ instruments such as a capital-income tax, and choose direct government involvement in education as a easier and simpler alternative. Moreover, it is expected that in the absence of a perfect capital market, the need for direct involvement in education is even higher.
} 
just about their own level of consumption but how that compares to those (from among their peers and the other consuming generation) consuming around them. Such an intra and intergenerational consumption externality is responsible for the possibility that agents may over or underaccumulate human and physical capital relative to a planner. In an endogenous growth setup, three possible capital accumulation regimes are observed. On one hand, when the social weight to the future generations is too low, competitive equilibrium overaccumulates both types of capital, and on the other hand, when it is too high, competitive equilibrium underaccumulates both types of capital. In between these extreme weights, it has been shown that in the competitive equilibrium there is overinvestment in physical capital but underinvestment in human capital. But if the agents' non-optimality in human capital accumulation has roots in consumption externality, the production of both types of capital differ from the social optimum in an unidirectional way. As is common in endogenous growth models, the requirement for standard structure of public pension benefits become weak as the social weight to the future generations increases in this model but more importantly, if only externalities are concerned, whenever there is a need for education subsidy, infusing public pension benefits is not recommended and vice-versa. 


\section{Appendix}

\section{Proof of Lemma 1:}

The proof is simple and straightforward. Taking the total derivative of either equation (8) or (19) gives

$$
\begin{gathered}
\phi^{\prime \prime}\left(e_{t}\right)\left[f\left(\bar{k}_{t+1}\right)-f^{\prime}\left(\bar{k}_{t+1}\right) \bar{k}_{t+1}\right] d e_{t}+\phi^{\prime}\left(e_{t}\right)\left[-\bar{k}_{t+1} f^{\prime \prime}\left(\bar{k}_{t+1}\right)\right] d \bar{k}_{t+1}-f^{\prime \prime}\left(\bar{k}_{t+1}\right) d\left(\bar{k}_{t+1}\right)=0 \\
\Rightarrow \frac{d \bar{k}_{t+1}}{d e_{t}}=\frac{\phi^{\prime \prime}\left(e_{t}\right)\left[f\left(\bar{k}_{t+1}\right)-f^{\prime}\left(\bar{k}_{t+1}\right) \bar{k}_{t+1}\right]}{f^{\prime \prime}\left(\bar{k}_{t+1}\right)\left[1+\phi^{\prime}\left(e_{t}\right) \bar{k}_{t+1}\right]}
\end{gathered}
$$

Given the property of $f$ and $\phi$, I clearly have $\frac{d \bar{k}_{t+1}}{d e_{t}}>0, \forall t$, for both the CE and SP. Note that since $\frac{d \bar{k}_{t}}{d e_{t-1}}=\frac{\frac{\partial k_{t}}{\partial e_{t-1}} h_{t}-\frac{\partial h_{t}}{\partial e_{t-1}} k_{t}}{h_{t}^{2}}, \frac{d \bar{k}_{t}}{d e_{t-1}}>0 \Rightarrow \frac{\partial k_{t}}{\partial e_{t-1}} h_{t}-\frac{\partial h_{t}}{\partial e_{t-1}} k_{t}>0 \Rightarrow \frac{\partial k_{t}}{\partial e_{t-1}} \frac{e_{t-1}}{k_{t}}-$ $\frac{\partial h_{t}}{\partial e_{t-1}} \frac{e_{t-1}}{h_{t}}>0$ and thus $\eta_{k, e}>\eta_{h, e}$.

To prove $\frac{d \bar{k}^{S P}}{d \lambda}>0$, at the steady state, I take the total derivative of equation (24) which implies that

$$
f^{\prime}\left(\bar{k}^{S P}\right) d \lambda+\lambda f^{\prime \prime}\left(\bar{k}^{S P}\right) d \bar{k}^{S P}=0 \Rightarrow \frac{d \bar{k}^{S P}}{d \lambda}=\frac{-f^{\prime}\left(\bar{k}^{S P}\right)}{\lambda f^{\prime \prime}\left(\bar{k}^{S P}\right)}>0 .
$$

Using (A.1) and (A.2) I clearly have $\frac{d e^{S P}}{d \lambda}>0$.

\section{Proof of Lemma 2:}

Suppose not. Let there exist $\bar{\lambda}$ and $\widetilde{\lambda}, \bar{\lambda} \neq \widetilde{\lambda}$ so that $\frac{u_{\widetilde{c}_{t}}^{C E}}{u_{\widehat{d}_{t+1}}^{C E}}=\frac{u_{\widetilde{c}_{t}}^{S P}}{u_{\widehat{d}_{t+1}}^{S P}}$ holds for both $\bar{\lambda}$ and $\tilde{\lambda}$. Without loss of generality, I assume that $\bar{\lambda}>\widetilde{\lambda}$. But if $\bar{\lambda}>\widetilde{\lambda}$, using Lemma 1 , I have $\bar{k}^{S P}(\bar{\lambda})>\bar{k}^{S P}(\widetilde{\lambda})$. But on the other hand, both $f^{\prime}\left(\bar{k}^{C E}\right)=f^{\prime}\left(\bar{k}^{S P}(\bar{\lambda})\right) \Delta$ and $f^{\prime}\left(\bar{k}^{C E}\right)=$ $f^{\prime}\left(\bar{k}^{S P}(\widetilde{\lambda})\right) \Delta$ imply that $\bar{k}^{S P}(\bar{\lambda})=\bar{k}^{S P}(\widetilde{\lambda})$ given $f^{\prime}>0$. Hence the contradiction.

\section{Proof of Lemma 3:}

The proof is straightforward. It can directly be constituted from equation (19). Given $\bar{k}^{S P}(\widehat{\lambda})=\bar{k}^{C E}$, I have

$$
\begin{aligned}
\phi^{\prime}\left(e^{S P}(\widehat{\lambda})\right) & =\frac{f^{\prime}\left(\bar{k}^{S P}(\widehat{\lambda})\right)}{f\left(\bar{k}^{S P}(\widehat{\lambda})\right)-f^{\prime}\left(\bar{k}^{S P}(\widehat{\lambda})\right)\left(\bar{k}^{S P}(\widehat{\lambda})\right)}=\frac{f^{\prime}\left(\bar{k}^{C E}\right)}{f\left(\bar{k}^{C E}\right)-f^{\prime}\left(\bar{k}^{C E}\right)\left(\bar{k}^{C E}\right)}=\phi^{\prime}\left(e^{C E}\right) \\
& \Rightarrow e^{S P}(\widehat{\lambda})=e^{C E} \text { by the property of } \phi .
\end{aligned}
$$




\section{Proof of Proposition 1:}

For any $\bar{\lambda}$, only three possible situations can be observed: case (a) when $\Delta>1$, case (b) when $\Delta<1$ and case (c) when $\Delta=1$. In case (a), I have $f^{\prime}\left(\bar{k}^{C E}\right)>f^{\prime}\left(\bar{k}^{S P}(\bar{\lambda})\right)$ which implies that $\bar{k}^{C E}<\bar{k}^{S P}(\bar{\lambda})$. But $\bar{k}^{C E}<\bar{k}^{S P}(\bar{\lambda})$ implies that $e^{S P}>e^{C E}$ and thus $h^{S P}(\bar{\lambda})>$ $h^{C E}$. Therefore $h^{S P}(\bar{\lambda})>h^{C E}$ and $\bar{k}^{C E}<\bar{k}^{S P}(\bar{\lambda})$ gives $k^{S P}(\bar{\lambda})>k^{C E}$. Similarly, in case (b), I can show that $k^{C E}>k^{S P}$ and $h^{C E}>h^{S P}$. It is easy to check that in case (c), $k^{C E}=k^{S P}$ and $h^{C E}=h^{S P}$ hold. Therefore, for each $\Delta$ such that at its corresponding $\bar{\lambda}, k^{C E} \neq k^{S P}$ and $h^{C E} \neq h^{S P}$ hold, $k^{C E}$ and $h^{C E}$ differ from $k^{S P}$ and $h^{S P}$ in the same direction; either both are lower, that is, $k^{C E}<k^{S P}$ and $h^{C E}<h^{S P}$ as in case (a) or both are greater, that is, $k^{C E}>k^{S P}$ and $h^{C E}>h^{S P}$ as in case (b). Hence the proof.

\section{Proof of Corollary 1:}

This follows from the proof of Proposition 1.

\section{Proof of Proposition 2:}

I establish the result for $\lambda>\bar{\lambda}$ and claim the opposite result holds for $\lambda<\bar{\lambda}$. When $\lambda>\bar{\lambda}$, I must have $\bar{k}^{S P}(\lambda)>\bar{k}^{S P}(\bar{\lambda})$ since I already have proved $\frac{d \bar{k}^{S P}}{d \lambda}>0$ in Lemma 1 . We know that only three situations are possible; case (a) when $\Delta>1$, case (b) when $\Delta<1$ and case (c) when $\Delta=1$. In case (a), I must have $\bar{k}^{S P}(\lambda)>\bar{k}^{S P}(\bar{\lambda})>\bar{k}^{C E}$. Since Lemma 1 holds, this in turn implies that $h^{S P}(\lambda)>h^{C E}$ and thus I also have $k^{S P}(\lambda)>k^{C E}$. Note that in case (c), $\bar{k}^{S P}(\lambda)>\bar{k}^{S P}(\bar{\lambda})=\bar{k}^{C E}$ holds. This by the virtue of Lemma 1 means that $h^{S P}(\lambda)>h^{C E}$ and therefore $k^{S P}(\lambda)>k^{C E}$. But when case (b) occurs, note that (from Proposition 1) if $\lambda=\bar{\lambda}$, we have $k^{C E}>k^{S P}(\bar{\lambda})$ as well as $h^{C E}>h^{S P}(\bar{\lambda})$. Since both $k^{S P}$ and $h^{S P}$ are continuous in $\lambda$, there exists a $\lambda_{+}, 1>\lambda_{+}>\bar{\lambda}$, such that $k^{C E}=k^{S P}\left(\lambda_{+}\right)$and $h^{C E}=h^{S P}\left(\lambda_{+}\right)$hold. Furthermore, this implies that for all $\lambda>\lambda_{+}, k^{C E}<k^{S P}\left(\lambda_{+}\right)$and $h^{C E}<h^{S P}\left(\lambda_{+}\right)$. Hence for $\lambda>\bar{\lambda}$, I have shown that there does not exist any situation where $h^{C E}$ and $k^{C E}$ differ from respective $h^{S P}$ and $k^{S P}$ in opposite directions. I omit the proof for $\lambda<\bar{\lambda}$ since it is clear that exactly the opposite results hold in this situation. Hence the proof.

\section{Proof of Corollary 2 and Corollary 3:}

These follow from the proof of Proposition 2. 


\section{References}

[1] A. Abel, Optimal Taxation When Consumers Have Endogenous Benchmark Levels of Consumption, Review of Economic Studies 72 (2005), 21-42.

[2] D. Acemoglu, J. Angrist, How Large Are Human-Capital Externalities? Evidence from Compulsory Schooling Laws, NBER Macroeconomics Annual (2000), pp 9-59.

[3] J. Alonso -Carrera, J. Caballe, X. Raurich, Estate taxes, consumption externalities, and altruism, Journal of Public Economics 92 (2008), 1751-64

[4] R. Barnett, J. Bhattacharya, Rejuveniles and Growth. European Economic Review 52 (2008)1055-1071.

[5] G. S. Becker, Human capital: A theoretical and empirical analysis with special relevance to education, second edition, NBER, New York.(1975).

[6] M. Boldrin, A. Montes, The Intergenerational State Education and Pensions, Review of Economic Studies 72 (2005), 651-664.

[7] D. Card, The Causal Effect of Education on Earnings, in: O. Ashenfelter, D. Card (Eds.), Handbook of Labor Economics 3A, Amsterdam, North Holland, 1999.

[8] A. Ciccone, G. Perri, Identifying Human-Capital Externalities: Theory with Applications, Review of Economic Studies 73 (2006), 381-412.

[9] T. S. Dee, Are there civic returns to education?, Journal of Public Economics 88 (2004), 1697-1720.

[10] P. A. Diamond, National debt in a neoclassical growth model. American Economic Review 55 (1965), 1126-1250.

[11] F. Docquier, O. Paddison, P. Pestieau, Optimal accumulation in an endogenous growth setting with human capital, Journal of Economic Theory 134 (2007), 361-378.

[12] S. N. Durlauf, M. Fafchamps, Social Capital, in: S. Durlauf, P. Aghion (Eds.), Handbook of Economic Growth, 2004.

[13] O. Galor, O. Moav, Das Human Kapital: A Theory of the Demise of the Class Structure, Review of Economics Studies 73 (2006), 85-117.

[14] J. J. Heckman, Policies to Foster Human Capital, Research in Economics 51 (2000), $3-56$. 
[15] J. J. Heckman, Klenow, Peter J.: Human Capital Policy, in: M. Boskin (Eds ), Policies to Promote Capital Formation, Stanford, CA, Hoover Institution,1998.

[16] D. A. Kodde, J. M. M. Ritzen, The demand for education under capital market imperfections, European Economic Review 28 (1985), 347-362.

[17] F. Lange, R. Topel, The Social Value of Education, in: E. Hanushek, F. Welch (Eds.), Handbook of the Economics of Education. Amsterdam, Elsevier, pp 459-509, 2006.

[18] R. Layard, Human satisfactions and public policy, The Economic Journal 90 (1980), 737-750.

[19] R. E. Lucas, On the mechanics of economic development, Journal of Monetary Economics 21 (1988), 3-42.

[20] R. D. Putnam, R. Leonardi, R. Y. Nanetti, Making Democracy Work: civic traditions in Modern Italy. Princeton University Press, Princeton, 1993.

[21] F. W. Richter, C. Braun, Efficient subsidization of human capital accumulation with overlapping generations and endogenous growth, CESIFO working paper (2010).

[22] J. Rudd, Empirical Evidence on Human Capital Spillovers, Finance and Economics Discussion Series 2000-46, Board of Governors of the Federal Reserve System, Washington, 2000.

[23] T. W. Schultz, Investment in human capital, American Economic Review 51 (1961), $1-17$.

[24] C. Turner, R. Tamura, S. E. Mulholland, S. Baier, Education and Income of the States of the United States, Journal of Economic Growth 12 (2007), 1840-2000.

[25] S. J. Yamarik, Estimating Returns to Schooling from State-Level Data: A MacroMincerian Approach, The B.E. Journal of Macroeconomics 8, 1 (Contributions) (2008), Article 23.

[26] J. Zhang, Optimal debt, endogenous fertility, and human capital externalities in a model with altruistic bequests, Journal of Public Economics 87 (2003), 1825-1835. 